\title{
LA CONSTRUCCIÓN VIRTUAL DEL CUERPO EN FACEBOOK CHAT: \\ perfil, nicknames y avatares
}

\author{
Christian Giovanny Miranda Gaibor* \\ Nelly Gabriela Guamán Guadalima** \\ Christian Nivardo Ortiz Chamba***
}

\section{Resumen}

El artículo analiza la construcción virtual del cuerpo en Facebook Chat, haciendo uso de una etnografía de carácter virtual enfocado desde tres aristas: el perfil del usuario, los nicknames y los avatares. Para ello se investigó a usuarios-finales del sexo masculino y femenino, entre los 13 a 59 años de edad, de un nivel socio-económico medio alto y alto; concluyéndose que el artefacto tecnológico reemplaza el cuerpo con todos los rasgos de naturaleza biológica, donde el chateo permite la creación de mundos posibles a través de la (re)creación de significados y representaciones; espacio en el cual, el cuerpo real y práctico es suplantado por el avatar como generación de una nueva forma de encarnación, donde el cuerpo se fusiona con la máquina y esta se convierte en su extensión.

La red social Facebook personaliza el interés de la Modernidad por construir un ser que vive y deja las huellas de su existencia en la memoria de los visitantes -historia cronológica personal. Entre las razones por las que los usuarios de Facebook publican información sobre ellos mismos es la noción de fama/reconocimiento que está detrás de todo ello.

Palabras clave: realidad virtual, representación virtual del cuerpo, Facebook Chat, perfil del usuario, los nicknames y los avatares.

\section{Recibido: Febrero 27, 2018 - Aceptado: Marzo 19, 2018}

*Mg. Christian Giovanny Miranda Gaibor. Magíster en Ciencias Sociales con mención en Comunicación - Facultad Latinoamericana de Ciencias Sociales. Licenciado en Comunicación Social - Universidad Central del Ecuador. Docente de la Universidad Técnica de Cotopaxi. Email: christian.miranda5477@utc.edu.ec

**Mg. Nelly Gabriela Guamán Guadalima. Docente de la Universidad Técnica de Ambato Orcid. https://orcid.org/0000-0002-5380-8877 ; Email: ng.guaman@uta.edu.ec

${ }^{* * *}$ Mg. Christian Nivardo Ortiz Chamba. Universidad Rey Juan Carlos. Máster en Investigación Aplicada a la Comunicación - Universidad Rey Juan Carlos (España). Licenciado en Relaciones Públicas - Universidad Técnica Particular de Loja (Ecuador).Email: cnortiz@gmail.com

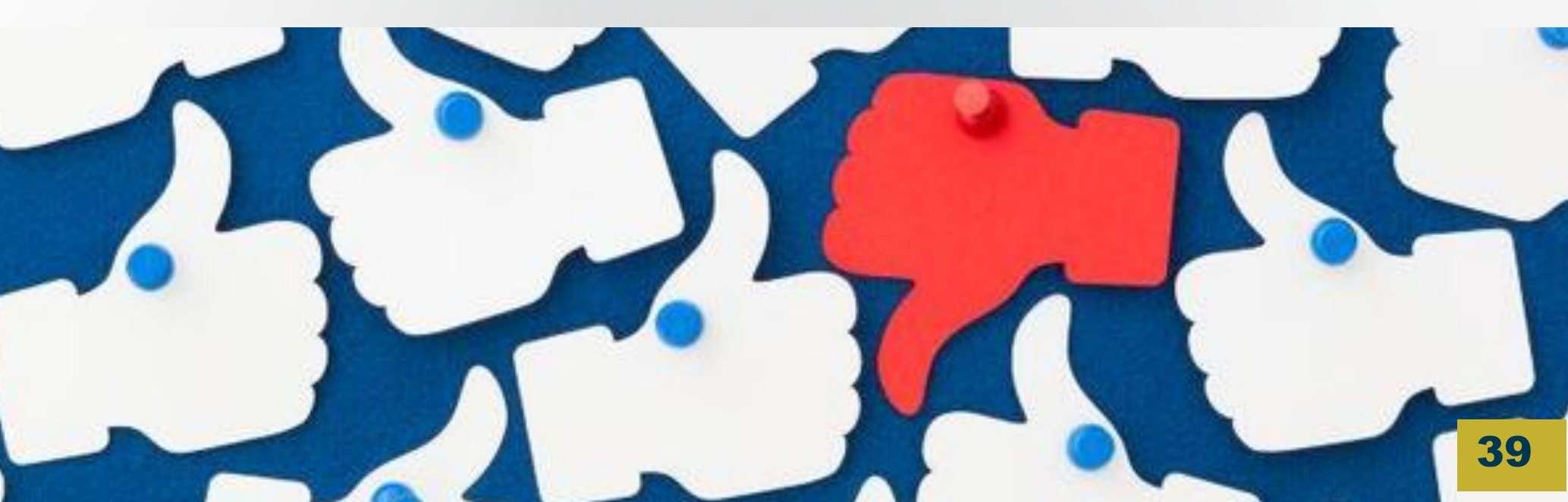




\section{BUILDING OF A VIRTUAL BODY ON FACEBOOK CHAT: profile, nicknames, and avatars}

\section{Summary}

This article analyzes the building of a virtual body on Facebook Chat, making use of an ethnography of virtual type focused from three edges: user profile, nicknames, and avatars. For this purpose male and female end users from upper middle and upper social level between the ages of 13 and 59 were inquired. It was concluded that the technological device replaces the body with all traits of a biological nature, where chatting allows the creation of possible worlds through recreation of meanings and representations, into a space where the real and practical body is supplanted by the avatar as the generation of a new form of incarnation that merges the body with the machine, becoming this in its extension.

Facebook network customizes Modernity interest in building a living being that leaves traces of existence in the visitors' memory - personal chronologic history. Behind the purposes of Facebook users about posting personal information, it is found the concept of fame and recognition.

Keywords: virtual reality, virtual representation of the body, Facebook Chat, user's profile, nicknames, avatars.

Received . February 27, 2018 - Accepted. March 19, 2018

\section{A CONSTRUÇÃO VIRTUAL DO CORPO EM FACEBOOK CHAT: perfil, mudanças e avatares}

\section{Resumo}

O artigo analisa a construção virtual do corpo em Facebook Chat, fazendo uso duma etnografia de caráter virtual enfocado desde três extremidades: o perfil do usuário, as mudanças e os avatares. Para isto foram investigados usuários-finais do sexo masculino e feminino, entre os 13 a 59 anos de idade, dum nível socioeconómico meio-alto e alto; concluindo-se assim que o dispositivo tecnológico substitui o corpo com todas as características de natureza biológica, onde o chateo permite a criação de mundos possíveis através da (re)criação de significados e representações; espaço no qual, o corpo real e prático é suplantado pelo avatar como geração dum modo novo de encarnação onde o corpo se funde com a máquina e esta se transforma em sua extensão.

A rede social Facebook personaliza o interesse da Modernidade para construir um ser que vive e deixa as impressões de sua existência na memória dos visitantes - história cronológica pessoal. Entre as razões pelas que os usuários de Facebook publicam informações sobre eles mesmos é a noção de fama/reconhecimento que fica atrás de tudo isto.

Palavras chaves: realidade virtual, arepresentação virtual do corpo, Facebook Chat, perfil do usuario, as mudanças e os avatares.

Recebido. Fevereiro 27, 2018 - Aceitado. Março 19, 2018 


\section{INTRODUCCIÓN}

La Modernidad postula un sueño de futuro de realización individual y grupal, ello implica que el ser humano hace su historia. Sin embargo, y por contradicción, este mismo sueño autodeterminativo se muestra como un espejismo donde las promesas emancipadoras siguen latentes y aún no terminan por satisfacerse; cimiento que se relaciona con la necesidad imperiosa de extender y universalizar la revolución tecnológica que ha generado cambios sustanciales en grupos sociales.

Así, aparecen nuevos usos y conocimientos incorporándonos al mundo del simulacro a través de la realidad virtual que encuentra su máximo exponente en la expansión de las redes sociales como Facebook, un entorno virtual que tiene claramente la intención de emular (imitar, simular) el mundo de los seres humanos; es decir, reproducir la vida social de las personas. De este modo, el artículo tiene como objetivo principal analizar la construcción virtual del cuerpo en Facebook chat, desde tres aristas: el perfil del usuario, los nicknames y los avatares.

Para la consecución de tal objetivo, en primera instancia se consideró necesario el análisis de conceptos fundamentales -representación, el cuerpo en los entornos virtuales, usos sociales de la tecnología, el chat, los nicknames, avatares y Facebook chat- donde se recurrió a entrevistas entre otros recursos técnicos utilizados para recolección de datos que son explicados en la parte correspondiente a Metodología partiendo de experiencias personales obtenidas a través de una investigación cualitativa, en la que se revela las estrategias empleadas para la representación y posterior presentación mediante su perfil, avatar o cualquier representación icnográfica, pues estos agrupan lo que se cree la persona es.

Las conclusiones se presentan de manera cronológica; es decir, reunidas de manera general y secuencial a los temas que componen esta obra.

\section{METODOLOGÍA}

La base del estudio se sostiene sobre una densa etnografía virtual, cuyo proceso se corresponde con el sistemático trabajo de campo, donde el producto resultante se encuentra contenido en esta investigación. La proximidad con los sujetos de estudio fue fundamental para obtener un resultado de registro satisfactorio.

Como modelo teórico general se ha aplicado fundamentalmente el hermenéutico o interpretativo procurando establecer interdependencias, relaciones, vínculos entre variables que faciliten la comprensión del objeto de estudio. No obstante, no se ha despreciado el modelo explicativo cuando la ocasión ha sido favorable, de cara a establecer relaciones de causalidad (causaefecto) que llevaran a demostrar la lógica del sistema estudiado.

El valor primordial del presente trabajo de investigación se sitúa; por un lado, en la descripción de los hechos observados como en su interpretación etic, cuyo rigor queda marcado por los límites que ofrezcan los datos, a los que se ha procurado extraer y utilizar al máximo, sin cometer excesos, para evitar llegar a aquello que tan solo es fruto de la imaginación y; por el otro, desde la formación teórica (perspectiva emic) en la revisión sobre representación, virtualidad y corporeidad que se han generado en distintas áreas de conocimiento y que, sin duda, aportaron a la comprensión de los discursos y comportamientos observados.

De este modo, los recursos técnicos empleados para la obtención de datos fueron casi exclusivamente cualitativos desde donde se empleó la observación científica participante y no participante dependiendo de la situación (necesidades), pero, invariablemente estructurada y sistemática alrededor de parámetros, actitudes y comportamientos. Además, se utilizó dos tipos de cuadernos de campo: uno de carácter técnico, ajustado a un elaborado protocolo de observación; y otro de carácter más íntimo en donde la cuestión emocional y las impresiones personales del investigador adquirieron protagonismo.

Además, se usó la entrevista intensiva en profundidad bajo un carácter abierto en formulación de preguntas y un desarrollo temporal indeterminado, marcado en cada caso por el grado de significación de datos obtenidos en conversaciones y (ciber) conversaciones. Estas se prolongaron durante numerosos días tratando de no forzar a los interlocutores. 


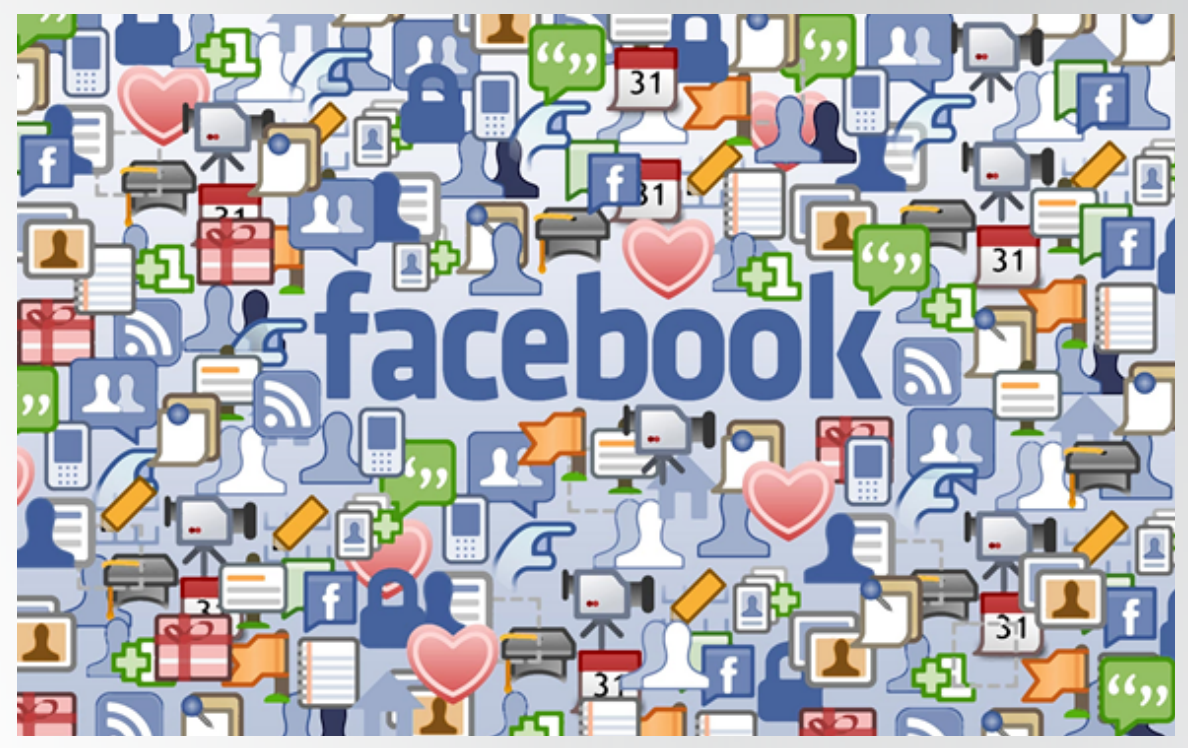

"Toda realidad es representada, apropiada por el individuo o el grupo y reconstruida en su sistema cognitivo, integrada en su sistema de valores que depende de su historia y del contexto social que le circundan" Jodelet (1988, p. 42).
Como se puede apreciar por las técnicas de datos utilizadas, se pretendió obtener información minuciosa, por un lado del comportamiento, y por otro del discurso (lo que las personas dicen que hacen, piensan y sienten), para posteriormente conjugarlos y comprender cómo construyen y/o auto representan su cuerpo en amplios sentidos.

Finalmente el estudio investigó a usuarios-finales del sexo masculino y femenino, entre los 13 a 59 años de edad (con un total de 25 entrevistas: 12 hombres y 13 mujeres), que pertenecían a un nivel socio-económico medio alto y alto, donde los usuarios-finales son frecuentes en Facebook. Estas conexiones se llevaron a cabo durante las noches y madrugadas, también, durante el día y la tarde y fines de semana o feriados.

\section{DESARROLLO}

\subsection{LA REPRESENTACIÓN}

Las representaciones plantean que "no hay distinción alguna entre los universos exterior e interior del individuo (o del grupo). El sujeto y el objeto no son fundamentalmente distintos" (Balandier, 1994, p. 32).

Ese objeto está siempre inscrito en un contexto activo y la relación sujeto-objeto determina al objeto mismo, pues una representación, siempre es la representación de algo para alguien. Esta relación sujeto-objeto, lleva a otorgar un status nuevo a lo que se identifica como "realidad objetiva" y que es definida por los componentes objetivos de la situación y del objeto.
Por lo tanto, esta realidad compartida y arreglada es para las personas su verdad. La representación reestructura la realidad para, a la vez, permitir integración de características objetivas del objeto, de experiencias anteriores del sujeto, y de su sistema de normas y actitudes. Esto permite definirla como:

\footnotetext{
"una visión funcional del mundo que permite al individuo o al grupo conferir sentido a sus conductas, y entender la realidad mediante su propio sistema de referencias, adaptar y definir de este modo un lugar para si" Yubiets (1997, p. 3).
}

Perolas representaciones "no son exclusivamente cognitivas, también lo son sociales" (Abal, 2004, p. 106), lo que hace precisamente su especificidad con otras producciones o mecanismos cognitivos. El análisis y comprensión de representaciones y su funcionamiento suponen un doble enfoque socio cognitivo: lo cognitivo y lo social como componentes esenciales de la representación. Así reflejado: el componente cognitivo en la representación supone, "un sujeto activo, y tiene desde ese punto de vista una textura psicológica" (Berger, 1998, p. 60), sometida a las reglas que rigen los procesos cognitivos. 


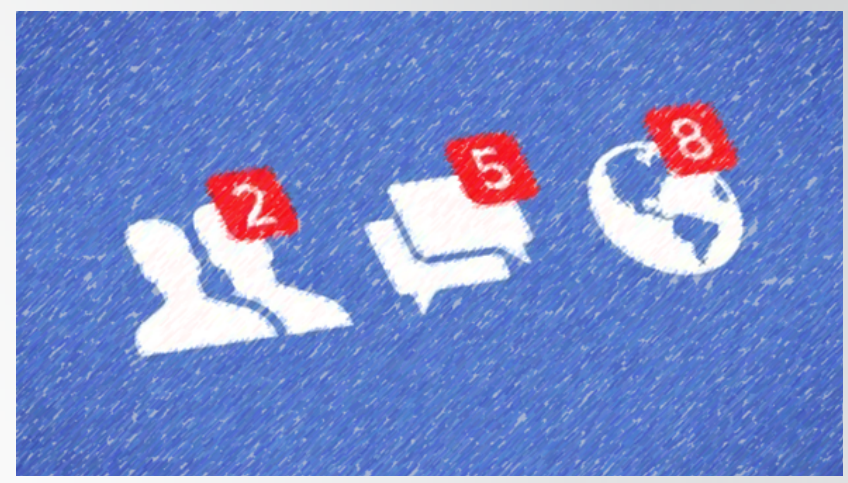

El componente social en la representación admite la puesta en práctica de esos procesos cognitivos, está determinada directamente por las condiciones en que una representación se elabora o se transmite. "esta dimensión social genera reglas que pueden ser muy distintas de la lógica cognitiva" (Balandier, 1994, p. 49).

La coexistencia de ambas permite dar cuenta y comprender por ejemplo por qué la representación integra a la vez lo racional y lo irracional. Pero también por qué tolera e integra contradicciones aparentes y por qué los razonamientos que genera pueden aparecer como ilógicos o incoherentes. A la vez esas contradicciones o ilogismos en realidad solo son aparentes, puesto que "una representación es un conjunto organizado y coherente" (Jodelet, 1988, p. 99).

\subsection{EL CUERPO EN LOS ENTORNOS VIRTUALES}

La problemática del cuerpo en entornos virtuales y digitales ha sido pensada desde la condición de movilidad y mutación. "Gracias al empleo de las nuevas tecnologías de la comunicación dejamos de lado las nociones de naturaleza biológica y condiciones geográficas tiempo y espacio" (Rheingold, 1995, citado en Levy, 1995). Para movilizarse en el ciberespacio es necesario entrar en el terreno de lo onírico y con imaginación "trabajar en el cambio de la identidad sexual, edad y rasgos físicos característicos -peso, estatura, medidas, entre otros- desaparecen y con ello, las huellas humanas dejan de interferir en el encuentro, en oposición de las interrelaciones cara a cara" (Goffman, 1963).

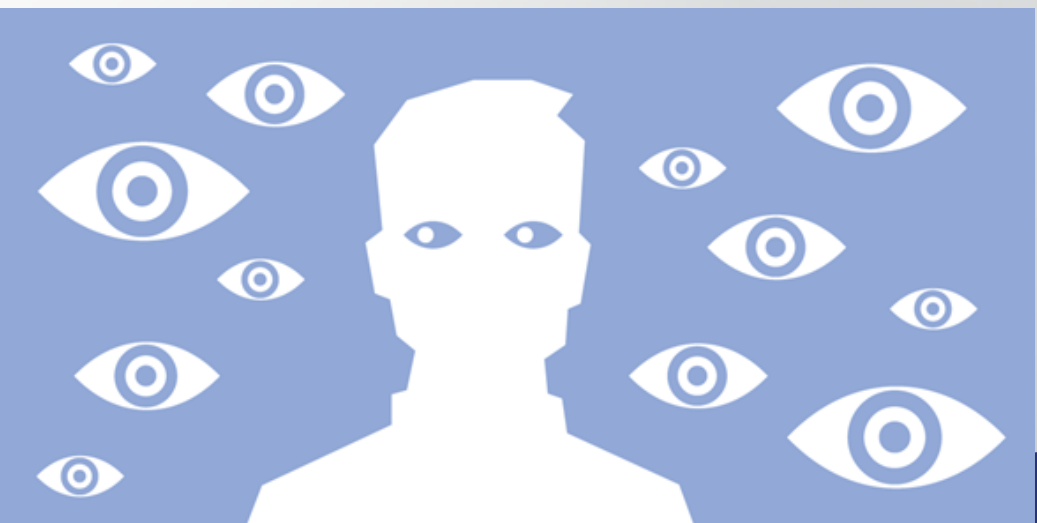

Así, "la red es el estar en común, o estar juntos, y aún más simplemente o de manera más directa, estar entre varios (être à plusieurs). Es ser tocado y es tocar" (Sánchez, 2001, p. 55); por lo que la experiencia de estar o vivir en red posibilita un estado ideal de sentirse parte de, nosotros tocamos y somos tocados a través de lo que transita, sea mensajes e imágenes provocando reunión de cuerpos, sentidos, percepciones y emociones que tienen como único fin la acción; "pero lo que está en discusión es la próxima etapa de la evolución a través de la fusión entre la humanidad y la tecnología" (Le Bretón, 199, p. 19).

Estos avances tecnológicos alimentan el espejismo de descorporización, multicorporización y multipresencia en tiempo real, irrumpiendo la metáfora del beneficio mecánico. Pero en este interjuego entre realidad y fantasía aparece el nominativo de hipercuerpo de Levy (1995) refugiado en el deseo, el sueño, la ilusión y alimentado por la noción imaginaria de traspaso del cuerpo a un más allá, donde esta experiencia es el segmento perjudicial y contradictorio de la descorporización en entornos virtuales y digitales que ratifica al cuerpo su situación de ser un hipercuerpo navegando y expandido conectado con otras inteligencias colectivas o conectivas; sin embargo, el cuerpo de naturaleza biológica sigue siendo uno solo, por lo menos hasta hoy.

\subsection{REALIDAD Y SIMULACIÓN}

La realidad virtual "no se trata ya de imitación ni de reiteración, incluso ni de parodia, sino de una suplantación de lo real por los signos de lo real y, en corto circuito, todas sus peripecias" (Baudrillard, 1993, p. 17). Incorporamos al individuo al campo del simulacro: "simular es inventar o, mejor, aparentar y así eludir nuestra condición" (Paz, 1995, p. 46). Al penetrar en un mundo muchas veces ajeno a la realidad perceptible, se entra en el mundo del simulacro consciente y permitido.

La realidad virtual es simulación por computadora, dinámica y tridimensional, con alto contenido gráfico, acústico y táctil, orientado a la visualización de situaciones variables y complejas, durante la cual el usuario ingresa, a través del uso de sofisticados dispositivos de entrada, a mundos que aparentan ser reales, resultando inmerso en ambientes altamente participativos, cuya esencia es artificial. El propósito fundamental de 
la realidad virtual, es "producir un ambiente que sea indiferenciado a la realidad física" (Luhmann, 2000 , p. 172). Una cabina de simulación virtual de manejo de buques -por ejemplo-, donde el oficial se enfrenta a láminas con proyección computadorizada en tres dimensiones mostrando posibles estados, circunstancias, escenarios virtuales en plena maniobra. Así, "la simulación es una suplantación de lo real por los signos de lo real" (Baudrillard, 1978: 7).

\subsection{USOS SOCIALES DE LAS TECNOLOGÍAS}

McLuhan (1996) dirá que, gracias a la presencia tecnológica de los aparatos en la vida cotidiana, ahora somos extensiones de ellas. Señala:

(...) fisiológicamente, el hombre, en su uso normal de la tecnología (o de su cuerpo diversamente extendido), es constantemente modificado, a la vez que descubre un sinfín de maneras de modificarla a esta. El hombre se convierte, por decirlo así, en los órganos sexuales del mundo de la máquina, como la abeja lo es en el mundo vegetal, y ello le permite fecundar y originar formas nuevas.

McLuhan (1996; p. 66)

Los usos sociales tienen que ver con el arte de hacer, con la cotidianidad creativa que no pasa por el discurso sino por las prácticas; se trata de maneras de hacer dependientes del contexto y cargadas de creatividad, el hacer, los modos de habitar, de leer, de hablar, prácticas que se hacen y se rehacen siempre en función del contexto y de sus interrelaciones con los demás. En los usos se reconocen acciones que tienen su formalidad y su nivel de inventiva propia, las cuales organizan el trabajo de lo que en los estudios de comunicación y cultura se conoce como consumo.

Los usos sociales significan unas formas de asumir, metaforizar y, si se quiere, desviar el orden dominante, hacerlo funcionar y apropiarlo según formas particulares. En este mismo proceso se encuentra el uso que hacen las personas de los contenidos que circulan por diversos medios y tecnologías; esa información y significaciones son objeto de manipulaciones por parte de los usuarios quienes hacen una fabricación a su manera de los contenidos recibidos.
Los usos implican entonces aprendizajes, apropiación, transformación, relación con el grupo social y sobre todo las prácticas sociales. "Constituyen acciones repetidas que derivan de saberes aprendidos en la empina de la cotidianidad" (Bourdieu, 1990, p. 27), son actos frecuentes no explicados por los sujetos; en este sentido, es todo lo que de la vida social se sabe hacer, pero no es necesario decir o explicar. Aunque en ciertas circunstancias prime la experiencia de cada persona.

\subsection{EL CHAT: UN ESPACIO DE ENCUENTRO}

Desde los años ochenta, existe al alcance de los usuarios de Internet; el chat, que en inglés significa charlar, trasladando esta definición al contexto latinoamericano cobra otra significación, convirtiéndose en el sitio o lugar virtual donde se recogen conversaciones masivas y privadas en línea; cuya particularidad es, la no presencia física de los involucrados.

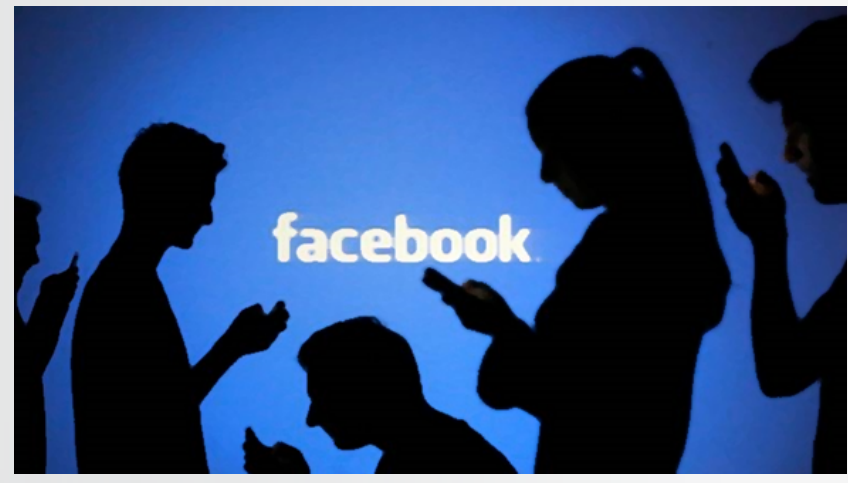

El chat es un espacio social de interacción entre anónimos muchas veces de forma pública o privada en texto escrito.

"En el chat para poder conversar tenemos que aprender a hablar con los dedos y escuchar con los ojos (...) es un espacio comunicativo con una elaboración narrativa, instantánea, fragmentaria, colectiva, efímera y vital".

Mayans (2002; p. 141)

Las características que se miran se comprimen a la decisión de los navegantes para dejar ver lo que ellos permitan. Las relaciones que se establecen en el chat se hacen con lo alterno del otro, por ello en un primer momento no interesa las características físicas de la persona que está al otro lado de la red, sólo cuenta la utilización del lenguaje y el papel que pueda llegar a jugar la imaginación en estas relaciones hipermediadas. 
Con el chat su cuerpo no es más un impedimento, porque este se virtualiza, se expande hacia la red, toma su dinamismo haciéndose múltiple al tener la posibilidad de estar tele-presente en diferentes espacios a los que se les ha deslocalizado; con esta corporalidad reinventada, el chat permite generar nuevas representaciones.

El Internet, y particularmente el chat al mismo tiempo que posibilita nuevas comprensiones de las relaciones interpersonales, comparte el trasfondo de las relaciones cara a cara, o dicho de otra forma, las relaciones se establecen a partir del mismo referente que se ubica al interior y exterior del mundo virtual, mediante la idealización del otro, no en el sentido de lo ideal como perfección sino en el sentido de que se construye una idea de la otra persona, lo cual implica que de alguna forma, todas las relaciones son virtuales. De modo que se puede decir que:

"el otro sí es una fantasía, porque solamente es una imagen, no es el otro, se tiene una imagen construida de este y con esa imagen es con la que se establecen relaciones"

Dertouzos (1998, p. 67) simbólicos que solo pueden ser comprendidos bajo ese espacio; la utilización de nombres propios de ese medio, como nicknames; el uso de referentes visuales que simulan la realidad compartida en la cotidianidad fuera de Internet, como la multimedia; la cercanía generada, a pesar de la distancia física y del desconocimiento que se podría tener por la otra persona con la que, en un momento dado, se establecería una relación por medio del chat u otras herramientas.

En el chat yo existo a partir del nickname, nick significa otro. Se entiende, por tanto, un nombre clandestino, ficticio para encubrir o mantener indefinida su personalidad; es decir, un seudónimo. Así, cuando se ingresa en una conversación virtual es imprescindible mostrarse y exhibirse con un nickname. Para David Bolter, el nick cumple con una función caracterizadora:

\begin{abstract}
"opera como una suerte de retrato comprimido al aparecer como nombre, apodo o título. Podríamos plantear que el nick elegido por alguien para chatear opera como primer elemento metadicursivo"
\end{abstract}

En el chat no hay referencias personales fija no existe cuerpo que identifique y sirva de referencia a los otros, se puede ser quien se desee ser, ya que fuera de la pantalla el reconocimiento y aceptación del otro como sí mismo, con su identidad, está mediado por el rostro; así, en el chat el cuerpo es reemplazado por una representación cualquiera que adopte el usuario o por el nickname, pues este agrupa lo que se cree la persona es, y que es mantenido dependiendo de la aceptación de otros navegantes, entendida como el acuerdo, explícito o implícito entre usuarios donde en ese espacio se puede ser vivido o recreado.

\subsection{LOS NICKNAMES (APODO O ALIAS)}

En la vida llamada en línea, las experiencias a pesar de no compartir los mismos elementos que constituyen las experiencias fuera de la red, posibilitan la construcción de relaciones interpersonales a niveles diferentes, en donde la percepción del otro y de su entorno está enmarcada por referentes representacionales y

Este nickname de igual forma ocupa la función del cuerpo en el espacio virtual, por lo que podría ser visto y pensado como el cuerpo virtual en la Internet. Por eso los nicks deben ser sugerentes, deben despertar fantasías sobre lo que cada quien es, cómo es, qué busca o qué le gusta.

En este contexto, la fragmentación del sujeto se manifiesta en forma de diferentes nicknames, que configuran distintas historias posibles de 
experienciar, cada una completa en sí misma pero que a la vez forma parte de una historia global, la vida de cada uno, en diferentes niveles. Sin embargo, cada vida/historia constituye un espacio de expresión y construcción de subjetividades, en los que se recrea "una cultura, con símbolos y significados a primera vista antagónicos, pero que se entrecruzan y dan lugar a nuevas narrativas en las que los protagonistas se comprenden como múltiples" (Bolter, 1991, p. 35).

\subsection{LOS AVATARES}

La palabra "avatar" significa transformación o cambio. Aplicado al chat, sería la transformación o el cambio que sufre el cuerpo en los entornos virtuales. Sin embargo, en inglés, quiere decir "personificación" o "manifestación corpórea de lo divino". "En sánscrito, la palabra avatara es utilizada para designar encarnación o descendencia de Dios" (Collins, 1996, p. 163). Así, un avatara es la representación visible que adoptan los dioses al descender al mundo material, la Tierra.

Avatara y avatar son manifestaciones de los seres divinos y humanos en espacios distintos. $Y$ así como un mismo Ser Divino puede revelarse en diferentes tiempos, lugares y circunstancias; un mismo cibernauta puede adoptar diversas corporalidades y personalidades en el mundo virtual.

Esta representación es un ícono simbólico seleccionado por nosotros mismos para interrelacionarse donde existen usuarios que buscan un avatar que de alguna forma los copie, mientras que otros escogen formas $y$ personalidades distintas e incluso opuestas a las que tienen en carne y hueso. Se da el caso, por ejemplo, de mujeres que tienen un avatar masculino, de quienes llevan una vida rutinaria y de bajo perfil pero añaden todo tipo de poderes sobrenaturales a su imagen virtual o también de discapacitados que se convierten en poderosos superhéroes dentro del ordenador.

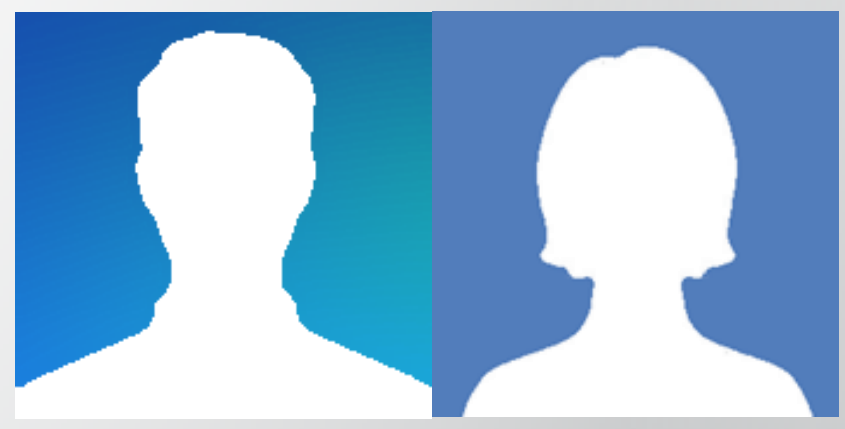

De nuevo, las carencias emocionales o de compañía en la sociedad actual intentan reducirse artificiosamente a través de elementos, representaciones y lugares que pretenden suplantar la vida off-line por una on-line "la flor natural ha sido sustituida por la flor de plástico" (Gubern, 2000, p. 219).

\subsection{FACEBOOK: TODO UN MUNDO VIRTUAL}

La realidad virtual se ha expandido por razón de los videojuegos en red, juegos de simulación y redes sociales que utilizan una interfaz gráfica para la representación de sus participantes. A través de las tecnologías digitales e Internet, estos mundos se han convertido rápidamente en espacios de socialización, de negocios, de educación, de investigación, entre otros.

Uno de los mundos virtuales que más se ha extendido en estos últimos años es Facebook y puede definirse como un mundo virtual (entorno digital) que facilita interactuar de forma libre, en un entorno en constante movimiento.

En la actualidad cuenta con cerca de 2.167 millones de usuarios activos en un mes, los usuarios de este sitio web se caracterizan por ser cibernautas que desean explorar, conocer e interactuar, prefieren conectarse varias veces al día a excederse más de 46 minutos. Pero a diferencia de otros mundos virtuales, que pueden ser no-digitales y completamente ficcionales, en Facebook se puede observar claramente la intención de emular (imitar, simular) el mundo de los seres humanos; es decir, Facebook reproduce la vida social de las personas.

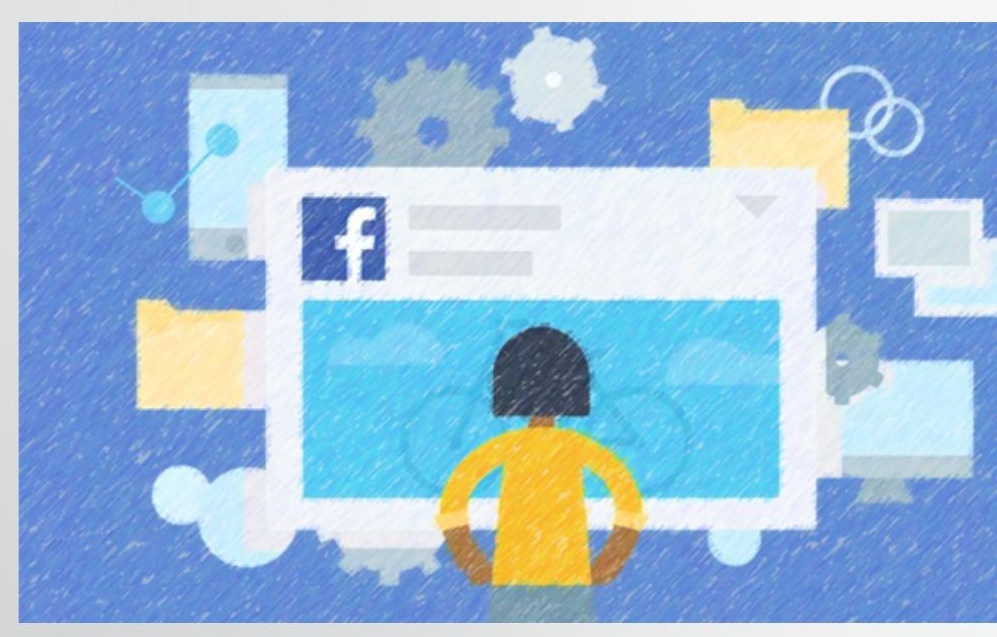




\section{RESULTADOS}

\subsection{PRESENTACIÓN DE LOS SUJETOS MEDIANTE SU PERFIL}

Las personas usan sus perfiles para ofrecer una mejor impresión de sí mismos, en algunos casos estos proporcionan imágenes bastante precisas de la personalidad de sus propietarios, ya sea porque la gente no trata de aparentar ser mejor de lo que es o porque tratan de hacerlo pero no lo consiguen.

En Facebook chat la iconografía -foto, avatartransmitida a través del perfil constituyen vínculos con el yo narrado y representado en imágenes -recuerdos- que describen hechos, lugares, historias, etc. Así define Verónica Luzuriaga a una fotografía:

"Una foto no es más que nuestra imagen de marca y el referente supremo del contacto humano. Miramos a la cara en primera instancia, es nuestra tarjeta de presentación y dicen "el espejo del alma", la verdad es que cada uno decide qué imagen quiere dar y la foto que eliges es lo que quieres proyectar"

[nickname: Lunita]

Las fotos proyectan el modo cómo comunicarse, quien es cada uno, qué hace, cuál es su rol y también cómo quiere ser tratado. Creándose expectativas en el observador, se le otorga información sobre cada uno para que pueda utilizar en una posible interacción cara a cara con la persona del perfil que está viendo.

La foto que se ubica en cada perfil delata y presenta al individuo, así narra un usuario final con el seudónimo Koppelman:

"Cuando pones una foto de cuando eras pequeño, buscas despertar la ternura en las mujeres, ofreces una tarjeta de visita no actualizada, soy yo pero ya no soy yo; cuando estás ligero de ropa es que estás orgulloso de tu cuerpo y aprovechas la ocasión para dar al planeta la oportunidad de disfrutarlo, de observarlo creando en el otro la envidia y el deseo en ellas... es más utilizado por las personas que buscan pareja y finalmente, sin foto simplemente no existes creas un clima de desconfianza y ocultamiento, esa es mi lectura de algunas fotografías"

[nickname: Koppelman]

Es así una especie de máscara, noción central en la perspectiva dramatúrgica. Goffman (1981) señala la relación entre la persona y el personaje que esta crea a través de la máscara. La persona se muestra ante los demás creando un personaje que de acuerdo al grupo de pares con el que interactúa la persona, esta máscara -como también los personajes- puede ir cambiando.

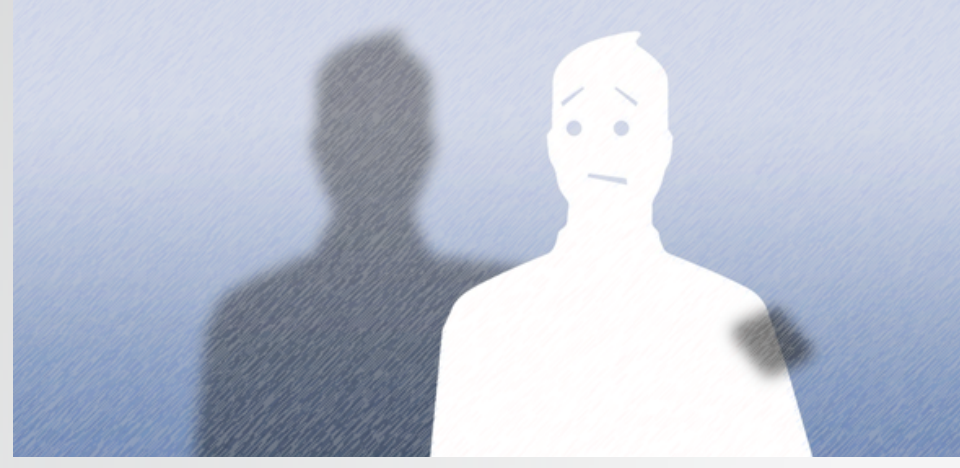

Como se aprecia, la plataforma -con todos sus servicios- se convierte así en un escenario donde no necesariamente se actúa. Este medio es fijo, es decir, siempre estará cuando la gente vea el perfil personal donde se puede usar de distintas maneras que favorezcan la fachada, cuya apariencia sirve para informar sobre el status y estado de ánimo. Todo esto ante un gran auditorio.

\subsection{PRESENTACIÓN DE LOS SUJETOS MEDIANTE SUS AVATARES}

En Facebook chat los usuarios emplean los elementos narrativos que proporciona el mundo virtual para construir sus propias narrativas acerca de sus avatares y su identidad corpórea. Facebook se ha caracterizado por ser un mundo abierto y las narrativas utilizadas tienen que ver más con su propia identidad corporal en el mundo real, potenciando aquellas que desean mostrar. Estas formas de ser en lo virtual están en un constante flujo entre lo real y lo virtual.

En las entrevistas realizadas los usuarios dijeron que a través del avatar intentan mostrase a sí mismos, son una representación de su ser en la que tratan de resaltar las características de su personalidad que más les gustan, pero en algunos casos también se asemejan a su apariencia en el mundo actual, aunque existen muchos avatares que son realmente trabajos de la imaginación; sin embargo a pesar de que los avatares no sean antropomórficos las elecciones que realizan los usuarios tienen que ver con las formas en que se perciben a sí mismos, con sus formas de ser. Así la representación de uno mismo es complicada, ya que se tiene que decidir la relación entre el yo real y el yo virtual. 
En la entrevista virtual realizada a Cristal sostuvo que:

\begin{abstract}
"El avatar es un yo idealizado y mi avatar refleja muchos aspectos de mí físicamente, es más o menos parecida, pero obviamente mi avatar tiene un cuerpazo, en Facebook chat hay de todo, tengo amigas que hacen que sus avatares se asemejen en lo más posible a sus cuerpos de vida real -flacas o gorditas, altas o bajas-. Otras obviamente le tiran a una idealización de su cuerpo. Se tiende a ver que los hombres si exageran en el cuerpo de sus avatares -hombros anchos, cinturitas, que dudo que muchos realmente tengan-"
\end{abstract}

\section{nickname: Cristal}

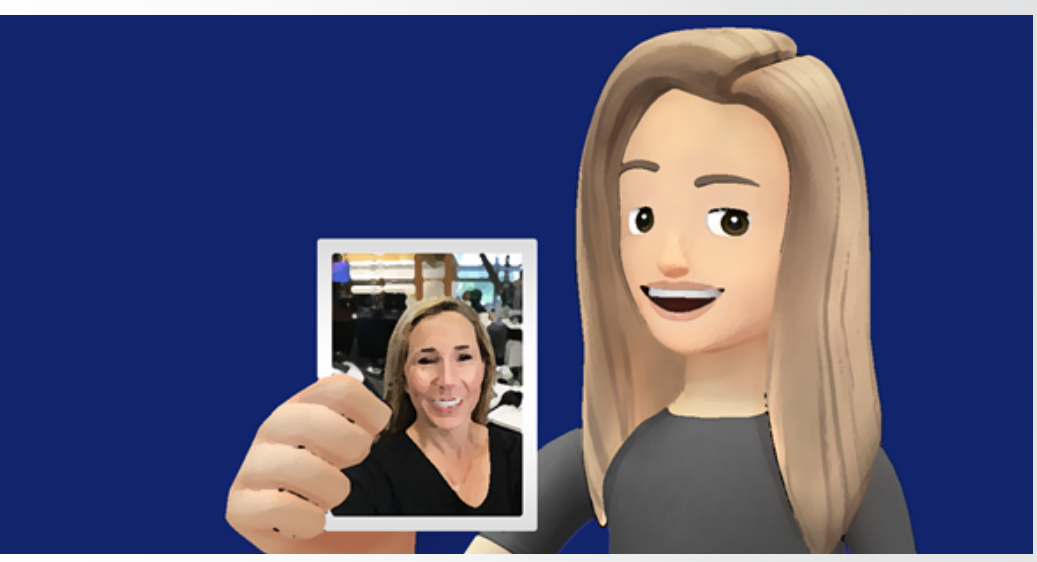

Lo significativo del avatar no es su hermosura, sino que comunique y proyecte fielmente lo que se desea que los otros vean. Y surge la pregunta ¿deseo lucir un estilo descomplicado? ¿Pretendo estar en boga o simular ser una persona circunspecta? etcétera.

A esta serie de interrogantes así responde Ernesto un joven promedio de edad:

"Los avatares me permiten construirme como yo quiero a la hora que yo quiero. Muestras cómo quieres ser visto ya que tú construyes tu imagen, cuerpo, apariencia, es decir, cómo te quieres mostrar, ser visto o identificado pero siempre en el Facebook chat debe estar una de las mejores imágenes que me represente ya que el avatar es mi marca, mi huella de presencia y existencia, es el vínculo por el cual voy a interactuar con otros usuarios"

Ahora bien, la interacción es muy diferente a las demás formas de tecnología relacionada con la comunicación. Esta interacción masiva se da con la intersubjetividad propia del yo natural, cosa que sucede en Facebook chat, ya que son los propios avatares quienes crean otra ecología de expresión, de difusión, de estructuración, de interacción y de observación.
El momento en que una persona entra en un mundo virtual tiene al menos dos cuerpos, un cuerpo físico y uno virtual. Aunque en los mundos virtuales la mayoría de usuarios no tienen un solo cuerpo virtual y una sola identidad, ya que muchas veces estos espacios permiten performar varios cuerpos digitales, en algunas ocasiones de formas complejas ya sea porque tienen múltiples avatares en un solo mundo virtual o porque participan en varios mundos virtuales al mismo tiempo, o porque si tomamos la definición de avatar de Stephen (2008) este puede ser una simple imagen, un nombre, un dibujo, una fotografía, etc. Otros se mantienen consistentemente dentro de los mundos virtuales con un solo avatar.

Facebook chat es un mundo virtual donde la presencia de los usuarios es visualmente representada a través de sus avatares. Estos son su apariencia la cual puede ser modificada infinidad de veces.

Esta virtualización de la presencia otorga una serie de licencias. Por ejemplo, se le permite al individuo replantear su identidad creando un avatar con el aspecto y la forma que se desee a eso sumarle un elemento más, la elección arbitraria de un nickname. Con este acto, se produce un desdoblamiento entre la identidad contenida en el cuerpo físico y una nueva identidad proyectada sobre el alias y el avatar; donde en las entrevistas la mayoría de personas señalaron que se crea una identidad a través del nick en los mundos virtuales, es a través de estas representaciones que se extienden los lazos sociales.

En general muchas de las personas pertenecientes al grupo que optaron por alguna de estas opciones, al ingresar al mundo con su nuevo avatar se identifican para los miembros del grupo con su antiguo nickname, incluso algunos a pesar del nuevo nickname siguieron siendo llamados por los miembros más cercanos por el antiguo. 


\section{3. (RE) INVENCIONES DEL CUERPO EN LOS ENTORNOS VIRTUALES}

El chat, ha provocado el desplazamiento de la corporalidad, de la presencia física, del espacio geográfico, o mejor aún, la ha (re) definido y ampliado, pues tecnologías como el teléfono, radio y la televisión, y aún más atrás, la escritura, posibilitaron ese desplazamiento. De hecho, el chat acompaña este proceso de (re)configuración del cuerpo provocando el ocultamiento y desvanecimiento de su naturaleza biológica.

En la comunicación mediada por computadora, en este caso el chat, se exhibe un fenómeno denominado la prueba de la existencia individual, expresado a través de avatares, fotografías, nicknames o simplemente, redactar en la red. Este acto de escribir en los espacios virtuales constituye una de las maneras de constar, dejar huella y coexistir con otros en estos universos.

El cuerpo se encuentra desplazado, oculto por las palabras de un texto digital, así que la visibilidad del otro, en contraste con la relación cara a cara, se ha transformado, lo cual implica, aquello que invita y convoca al otro a la interacción está despojado de los referentes corporales, y en este sentido las competencias narrativas/ comunicativas constituyen el punto clave del vínculo.

Según, Elisabeth Reid, "la conversación en los chats es en cierto modo sobrehumana, puesto que se produce no entre masas corpóreas, sino entre entidades místicas no muy distintas de la que convoca el médium en una sesión espiritista" (Reid, 1991: 167). Los participantes de la conversación aparecen en el encuentro a través de un nickname -cualquier seudónimo o representación en realidad-, al que se le presume una identidad con un cuerpo y un temperamento simbolizado en una imagen cualquiera.

El cuerpo es suplantado por el cuerpo interfase ser humano-máquina, como generación de una nueva forma de encarnación, que se instaura desde una confluencia simbólica: artificial $y$ natural/ virtual y real, donde el cuerpo se expande, se fusiona con la máquina, se complementa y se transforma.

\section{CONCLUSIONES}

El ser humano está rodeado de ordenadores y a través de estos, establece relaciones de intimidad y privacidad -vida online-. Así el computador es un ente (re) activo e interactivo, personificador de los límites de la vida off-line y evocador de nuevas actividades, experiencias, (re) construcciones y representaciones.

La conexión es una simulación del contacto y a la vez su negación. Se trata pues, no de la pérdida de la tierra, sino del lugar de referencia y de la correspondencia del cuerpo en ese lugar. A través de los sistemas de realidad virtual, los individuos viven una experiencia que involucra el cuerpo: la vista, el tacto, el oído. Esto obviamente cambia la concepción que se tiene del cuerpo.

La comunicación a través del computador, es una actividad desarrollada en tiempo real, es decir simultáneo, no precisa ni es afectada por la espacialidad. Es conversación escrita que lleva implícita espontaneidad de la oralidad sobre diversas temáticas. Su base es fundamentalmente visual. La entrada y salida de esta interacción se puede dar de forma secuencial, permaneciendo el tema en el ciberespacio aunque cambien permanentemente los interlocutores.

Cuando se piensa en las relaciones mediadas por computadora, se alude a un universo paralelo, en una realidad virtual, en el que los seres humanos se ven liberados de su corporalidad, virtualidad que es asumida como la verdadera esencia de su ser -desdoblamiento del alterego. Sin embargo la virtualización del cuerpo no puede reducirse a un proceso de desaparición o desmaterialización, sino, una (re)invención y/o (re)encarnación práctica-representativa y tecnológica del cuerpo.

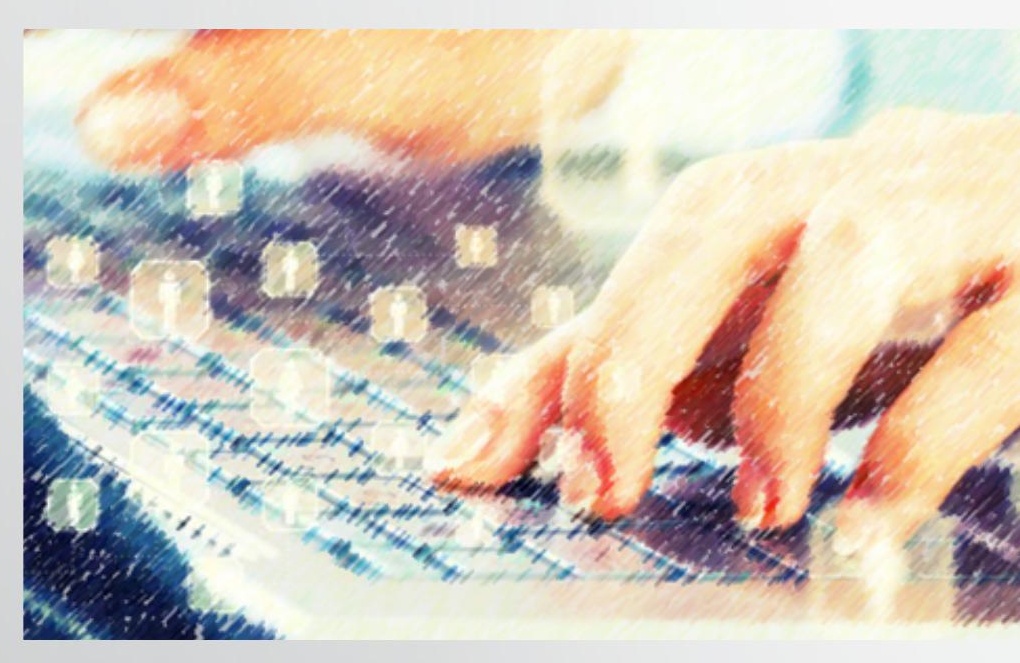


En el chat no se controla la narración, sino, la interacción; es decir, la autoría es compartida, pues las intervenciones de los usuarios finales dan la continuidad al relato, cuya característica es, improvisado y en muchos casos, sin aspiraciones estéticas, aunque no por ello insignificante siendo, además; un espacio autónomo, múltiple y dinámico. La ausencia de reglas y el ingreso irrestricto de audiencias hacen de este un medio público, donde los cibernautas tienen la posibilidad de jugar con la comunicación y las maneras de representarse.

El chat es el medio actual de comunicación de masas, que propició cambios en la historia de la comunicación humana, originando la escritura electrónica interactiva -la magia de la palabra narrada se transforma en texto escrito y la presencia física, en la interacción, convirtiéndose en iconos, tipografías, imágenes y/o representaciones-donde el cuerpo se encuentra desplazado, oculto por las palabras de un texto digital, así que la visibilidad del otro, en contraste con la relación cara a cara, se ha transformado. Implica que aquello que invita y convoca al otro en la interacción está despojado de los referentes corporales y en este sentido las competencias narrativas/comunicativas constituyen un referente de la interrelación.

El chateo motiva la imaginación, induce a la fantasía, distrae y cumple funciones similares a las del juego, en cuanto a manejo de la realidad a escala, permite la creación de mundos posibles a través de la (re)creación de significados y representaciones, ejercita diversos roles y desborda los límites que le hayan creado su verdadera identidad, apariencia física y esquemas de la vida cotidiana-mundos que posibilitan la aventura de salirse de la piel y (re)crearse otra vida-.

La desaparición de la presencia física -en este y otros mundos virtuales- entre usuarios finales interconectados requiere de nuevas y mejoradas prácticas, en cuanto a: lenguajes, códigos y formas de representación, empujándonos a una reacomodación de la relación del usuario con el uso de la escritura, de forma tal, estos modos de interrelación mediante texto electrónico cobran distancia entre la escritura tradicional y la ciberespacial -códigos propios que se alejan de las normas establecidas por la sintaxis y la ortografía priorizando la necesidad de agilidad y fluidez en el acto comunicativo.
Con el desvanecimiento de los límites físicos y temporales en el chat facilita la comunicación ilimitada en donde la interacción está mediada por el anonimato y la autonomía total de expresión. Por ello, el cambio de género y rol son posibles y justificables, ya que desde un punto de vista simplificado, todos jugamos a eso -en el ciberespacio-, sin embargo, la importancia que representa tener este contexto está dada por la oportunidad de hacer, decir y representarse como se quiere.

El avatar es una forma más que adoptan los seres humanos en los mundos virtuales, un modo más de representar el cuerpo dentro del chat, espacio en el cual, el cuerpo real y práctico es suplantado por el avatar como generación de una nueva forma de encarnación, que se instaura desde una confluencia simbólica entre lo artificial y lo natural, lo virtual y lo real, donde el cuerpo se expande, se fusiona con la máquina, se complementa y se transforma.

Facebook inclina sus servicios al consumo de tiempo: actualizando el perfil, respondiendo mensajes, subiendo/colgando fotografías, imágenes y/o videos, conociendo gente, (re) construyendo el avatar o cualquier actividad que cumpla la función de representación. Así la red social Facebook personaliza el interés de la Modernidad por construir un ser que vive y deja las huellas de su existencia en la memoria de los visitantes -historia cronológica personal.

Las razones por las que los usuarios de Facebook publiquen información sobre ellos mismos es la noción de fama/reconocimiento que está detrás de todo ello. Los mismos instrumentos utilizados por los famosos -publicación de fotografías o vídeos de interacciones sociales- están ahora al alcance de cualquiera. Para los usuarios, la red es el escenario, sus contactos no son amigos sino espectadores y el resto de usuarios, competidores por el mismo pedazo de fama y visibilidad.

El análisis de Facebook como artefacto sociotécnico es un ejemplo más de que la tecnología puede ejercer una gran influencia social, pero no en sí misma, sino en combinación con factores no necesariamente tecnológicos, sino sociales. Un artefacto puede ser producido y desarrollado por ingenieros, científicos o aficionados talentosos. 
Pero, cuando sale a la luz es (re)significado por diferentes grupos e individuos, cuyos intereses pueden y suelen ser diferentes a los inicialmente pensados por los inventores, y hasta entrar en conflicto unos con otros.

Las relaciones en Facebook chat son expresadas en forma opuesta a las relaciones off line: primero el cuerpo y después, lo que deseas manifestar, en el espacio virtual, este acto es al revés, primero exterioriza su opinión y luego, la presencia física. El artefacto tecnológico reemplaza el cuerpo con todos los rasgos de naturaleza biológica -tono de la voz, posturas corporales y gestos-, por lo ciberespacial y/o multimedia -digital-; es decir, texto electrónico y formas de representación que son posibles en este mundo virtual.

El enfoque socio-técnico no fue pensado para prever el futuro. Este se muestra abierto a la (re)definición y/o (re)estructuración en cualquier momento, de tal forma, que los grupos sociales relevantes (GSR) proporcionan significado al artefacto e, incluso, al ingreso imprevisto de nuevos actores al sistema. que borre sus imperfecciones. Lo que sucede es que está modelado/influenciado por aspectos de la vida off line: género, edad, cuestiones raciales, nacionalidad, experiencias, valores y conocimientos no se esfuman al ingresar en el ciberespacio.

En la red social, los individuos participan no a partir de lo que son, sino, por lo que pretenden o buscan ser, utilizan recursos basados en la apariencia y la capacidad para manejar las impresiones que los demás reciben de uno mismo.

Todo lo mencionado en la investigación no alcanza a contener lo que podría decirse acerca del sistema socio-técnico, cuyo elemento de análisis es Facebook chat. Son muchos los hitos históricos que podrían reseñarse y reflexiones teóricas que podrían anexarse. Pero, lo dicho alcanza para concluir que, a pesar de su popularidad, está lejos de considerarse estable. Cada uno de los elementos enumerados tiene sus propias fuentes de inestabilidad, pudiendo contribuir a un cambio extremo o, incluso, a la desaparición de todo el sistema.

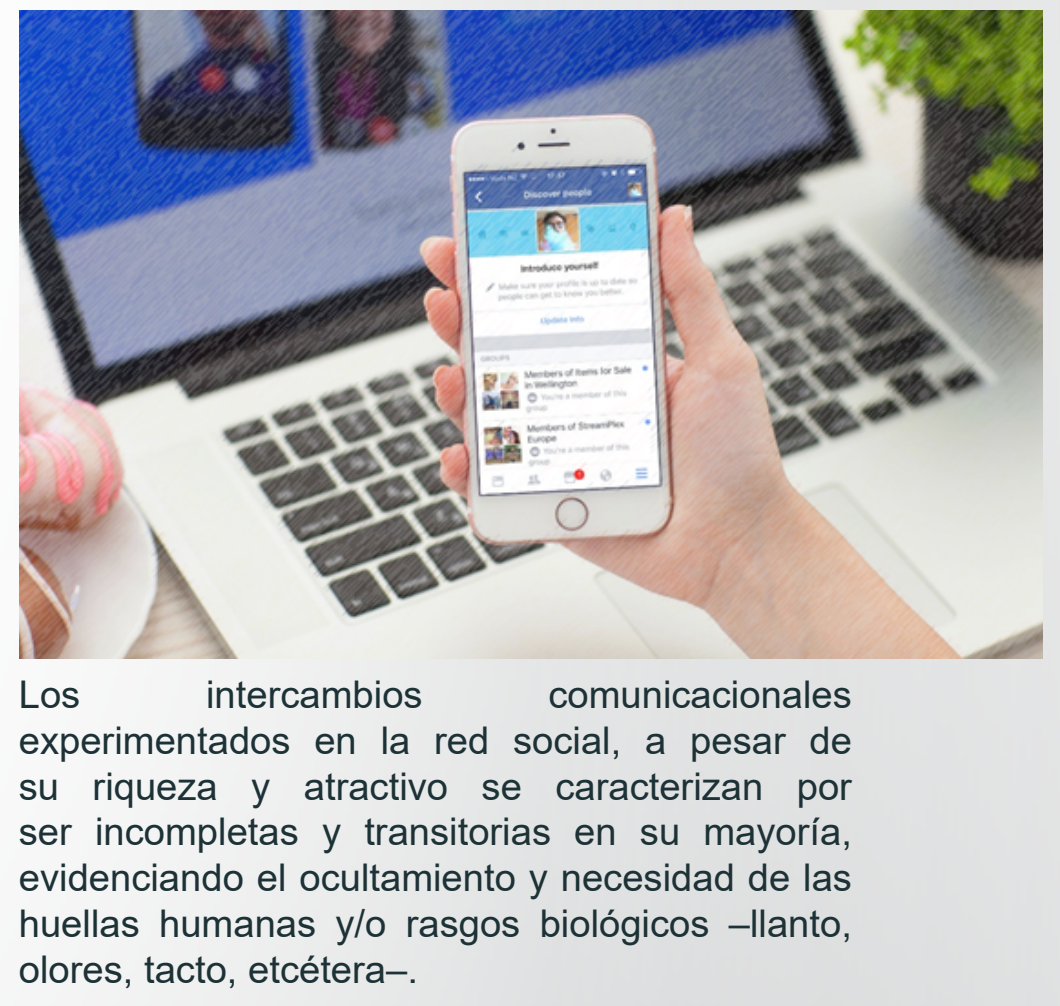

Mantener una conversación en Facebook chat demanda de un cuerpo digital presente y una noción de lugar representada, lo que genera otro tipo de interacción visual, donde las identidades en Facebook chat, son (re)construidas y no quedan liberadas del mundo off line; aunque, los usuarios apuestan a una (auto) representación simbólica

\section{BIBLIOGRAFÍA}

- Abal, J. La muerte y la resurrección de la representación política. Buenos Aires: Fondo de Cultura Económica, 2004.

- Balandier, G. El poder en escenas. De la representación del poder al poder de la representación. Barcelona: Paidós, 1994.

- Baudrillard, J. Cultura y simulacro. Barcelona: Kairós, 1978.

- Baudrillard, J. La ilusión del fin: la huelga de los acontecimientos. Barcelona: Anagrama, 1993.

- Berger, J. y Luckmann, T. La construcción social de la realidad. Buenos Aires: Amorrortu, 2006.

- Bourdieu, P. Sociología y Cultura. México: Grijalbo, 1990.

- Bolter, D. Writing Space. The computer, hypertext, and history of writing. New Jersey: Lawrence Erlbaum Associates, Publishers. LEA, 1991.

- Collins, H. "Interaction without society? What avatars can't do"? En Internet dreams. Archetypes, myths and metaphors, Mark Stefik (Comp.): Pp.186. Estados 
Unidos: Massachusetts Institute of Technology, 1996.

- Dertouzos, M. Qué será: cómo cambiará nuestras vidas el nuevo mundo de la informática. Bogotá: Planeta, 1998.

- Goffman, E. La presentación de la persona en la vida cotidiana. Buenos Aires: Amorrortu, 1981.

- Gubern, R. El eros electrónico. Madrid: Taurus, 2000.

- Jodelet, D. La representación: fenómenos, concepto y teoría. Barcelona: Paidós, 1988.

- Le Bretón, David. Antropología del cuerpo y modernidad. Buenos Aires: Nueva Visión, 1998.

- Lévy, P. Collective Intelligence: Mankind's Emerging World in Cyberspace, 1995.

- Luhmann, N. La realidad de los medios de masas. México: Antrophos - UIA, 2000.

- Mayans, J. Género chat. Barcelona: Gedisa, 2002.

- McLuhan, M. y Powers, B. La aldea global: transformaciones en la vida y los medios de comunicación en el siglo XXI. Barcelona: Gedisa, 1996.

- Sánchez, A. La era de los afectos en internet. México: Océano, 2001.

- Paz, O. Los hijos del limo. Barcelona: Seix Barral, 1987.

- Yubiets, E. Psicología Social y el estudio de las representaciones. Revista del Instituto de Investigaciones de la Facultad de Psicología, 2, 1997.

\section{Para citar este artículo:}

Miranda - Gaibor, C.; Guamán - Guadalima, N.; Ortiz - Chamba, C. (2018). LA CONSTRUCCIÓN VIRTUAL DEL CUERPO EN FACEBOOK CHAT: PERFIL, NICKNAMES Y AVATARES. . Revista Luciérnaga / Comunicación. Año 10, N19.

Págs.39-52.

DOI. 10.33571/revistaluciernaga.v10n19a3

OJS. http://revistas.elpoli.edu.co/index.php/luc/issue/archive Link. http://www.politecnicojic.edu.co/index.php/revista-luciernaga 